\title{
Development of emergency response tools for accidental radiological contamination of French coastal areas
}

\author{
Céline Duffa ${ }^{\text {a, * }}$, Pascal Bailly du Bois ${ }^{\mathrm{b}}$, Matthieu Caillaud ${ }^{\mathrm{e}}$, Sabine Charmasson ${ }^{\mathrm{a}}$, \\ Céline Couvez ${ }^{\mathrm{c}}$, Damien Didier ${ }^{\mathrm{d}}$, Franck Dumas ${ }^{\mathrm{f}}$, Bruno Fievet ${ }^{\mathrm{b}}$, Mehdi Morillon ${ }^{\mathrm{b}}$, \\ Philippe Renaud ${ }^{\mathrm{c}}$, Hervé Thébault ${ }^{\mathrm{a}}$ \\ a Institut de Radioprotection et de Sureté Nucléaire (IRSN), PRP-ENV/SESURE/LERCM, Antenne de Radioécologie Marine, Centre Ifremer, \\ Zone portuaire de Brégaillon, 13507 La Seyne sur Mer, France \\ ${ }^{\mathrm{b}}$ IRSN/PRP-ENV/SERIS/LRC, BP 10, Rue Max Pol Fouchet, 50130 Cherbourg-Octeville, France \\ ${ }^{\mathrm{C}}$ IRSN/PRP-ENV/SESURE/EC, 31 rue de l'écluse, BP 40035, 78116 Le Vésinet Cedex, France \\ d IRSN/PRP-CRI/SESUC/BMTA, 31, avenue de la Division Leclerc, BP 17, 92260 Fontenay-aux-Roses, France \\ e ACTIMAR, 36 quai de la Douane, 29200 Brest, France \\ f IFREMER - Centre Bretagne, ZI de la Pointe du Diable, CS 10070, 29280 Plouzané, France
}

\section{A R T I C L E I N F O}

\section{Article history:}

Received 14 January 2015

Received in revised form

24 April 2015

Accepted 29 April 2015

Available online 29 May 2015

\section{Keywords:}

Decision support

Marine

Modelling

Radioecology

Nuclear accident

\section{A B S T R A C T}

The Fukushima nuclear accident resulted in the largest ever accidental release of artificial radionuclides in coastal waters. This accident has shown the importance of marine assessment capabilities for emergency response and the need to develop tools for adequately predicting the evolution and potential impact of radioactive releases to the marine environment.

The French Institute for Radiological Protection and Nuclear Safety (IRSN) equips its emergency response centre with operational tools to assist experts and decision makers in the event of accidental atmospheric releases and contamination of the terrestrial environment. The on-going project aims to develop tools for the management of marine contamination events in French coastal areas. This should allow us to evaluate and anticipate post-accident conditions, including potential contamination sites, contamination levels and potential consequences.

In order to achieve this goal, two complementary tools are developed: site-specific marine data sheets and a dedicated simulation tool (STERNE, Simulation du Transport et du transfert d'Eléments Radioactifs dans l'environNEment marin).

Marine data sheets are used to summarize the marine environment characteristics of the various sites considered, and to identify vulnerable areas requiring implementation of population protection measures, such as aquaculture areas, beaches or industrial water intakes, as well as areas of major ecological interest. Local climatological data (dominant sea currents as a function of meteorological or tidal conditions) serving as the basis for an initial environmental sampling strategy is provided whenever possible, along with a list of possible local contacts for operational management purposes.

The STERNE simulation tool is designed to predict radionuclide dispersion and contamination in seawater and marine species by incorporating spatio-temporal data. 3D hydrodynamic forecasts are used as input data. Direct discharge points or atmospheric deposition source terms can be taken into account. STERNE calculates Eulerian radionuclide dispersion using advection and diffusion equations established offline from hydrodynamic calculations. A radioecological model based on dynamic transfer equations is implemented to evaluate activity concentrations in aquatic organisms. Essential radioecological parameters (concentration factors and single or multicomponent biological half-lives) have been compiled for main radionuclides and generic marine species (fish, molluscs, crustaceans and algae). Dispersion and transfer calculations are performed simultaneously on a 3D grid. Results can be plotted on maps, with possible tracking of spatio-temporal evolution. Post-processing and visualization can then be performed. (c) 2015 Elsevier Ltd. All rights reserved.

\footnotetext{
* Corresponding author.

E-mail address: celine.duffa@irsn.fr (C. Duffa).
} 


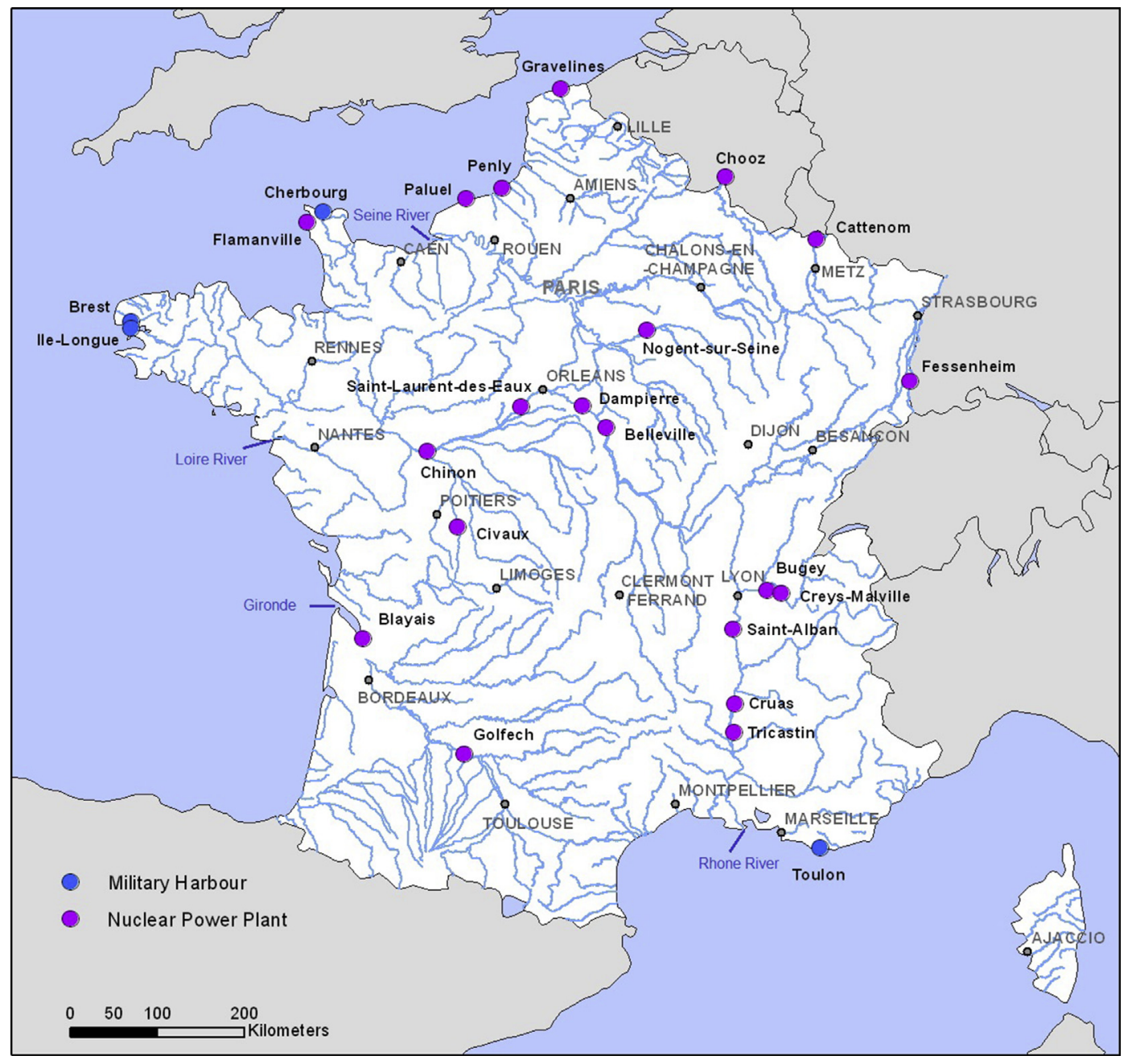

Fig. 1. French nuclear installations and coastal areas to be considered.

\section{Introduction}

Before 2011, some marine accidents involving radioactive material discharges have occurred in Europe (sinking of Mont Louis, Dover Strait, 1984; Carla, The Azores, 1997; Ece, English Channel, 2006), but their consequences were very limited. The nuclear accident at Fukushima in 2011 resulted in the largest ever accidental release of artificial radionuclides to coastal waters (UNSCEAR, 2014; Povinec et al., 2013, Science Council of Japan, 2014). The environmental and economic impact on Fukushima coastal area is enormous, particularly for fisheries (Okuda and Ohashi, 2012). It triggered an awareness of the need to set up operational tools for the management of a "marine crisis" and of possible lacks in the capability of many countries to efficiently manage such a radiological crisis.

About 130 nuclear reactors are operated in the European countries, 58 in France. Serious accidents on most of them would impact marine ecosystems, either through direct liquid release or aerosol fallout, or through transport of contaminated water masses by rivers. In addition, Atlantic and Mediterranean seas are the location of an intense maritime traffic including military nuclear powered ship traffic.

Although many research have been conducted in these areas to study behaviour of radioactivity in marine environment, the main knowledge concerns routine discharge of radionuclides.
There is limited expertise to provide information for decision makers to use in the event of accidental inputs of radionuclides into the sea.

Henceforth, it appears essential to take this risk of accidental contamination of coastal areas into account. This concerns particularly areas most potentially exposed to accidental releases from land-based nuclear installations. To ensure optimal preparedness in the event of a nuclear emergency affecting the marine environment, it is necessary to develop and implement specific tools to assess the evolution and impact of radioactive marine contamination events. This information will be used to facilitate decisionmaking during an emergency and could serve as a basis for postaccident sampling strategies leading to realistic environmental impact assessment.

The French Institute for Radiological Protection and Nuclear Safety (IRSN) has for many years now equipped its emergency response centre with operational tools to assist experts in the assessment of potential risks to local populations and terrestrial environments in the event of accidental release of radionuclides to the atmosphere. These tools were used in particular in the case of the Fukushima accident, among other things to simulate the short and long-range atmospheric dispersion of released radionuclides (Mathieu et al., 2011; Korsakissok et al., 2013; Saunier et al., 2013). Atmospheric dispersion computer codes are combined with computational modules designed to predict exposure 


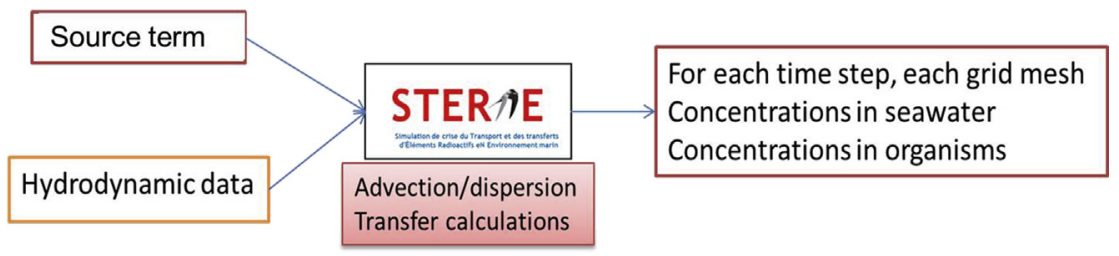

Fig. 2. Schematic diagram of STERNE implementation principle.

levels and activity concentrations in different environmental compartments.

This project aims to equip IRSN with supplementary tools for impact assessment and management in case of accidental marine contamination of French coastal areas. Given the length of its coastlines and the large number of nuclear installations in operation, it is extremely important for France to implement such capabilities. In addition to nuclear power plants located directly along the coast (Gravelines, Penly, Paluel and Flamanville NPPs, La Hague reprocessing plant), several nuclear installations are located along rivers that flow into the French Atlantic or Mediterranean coastal waters. Also to be noted is the presence of nuclear-powered ships in the military ports of Brest and Toulon. The maritime transport of nuclear materials must also be included in this inventory of potential source terms (see Fig. 1).

The first challenge in case of marine accidental contamination is to estimate the radionuclide concentrations in the different marine media and to identify the main stakes for public exposure first and for economic and environmental issues on a second stage.

This work aims to provide enhanced capabilities for predicting radionuclide dispersion in seawater and for assessing the potential impact on affected areas. In particular, specific tools and resources must be implemented to provide the following information:

- Initial estimates of expected activity concentrations in seawater, particularly near coastal areas, to effectively ensure the protection of populations directly or indirectly exposed to contaminated environments.

- Initial estimates of expected activity concentrations in aquatic organisms, particularly those intended for human consumption (fishing or aquaculture products).

- Contamination distribution and spatio-temporal evolution maps, to provide guidance for sampling strategies intended to characterise environmental impact.

- Detailed information regarding the site-specific environmental sensitivity and ecological, economic and health-related interests of identified areas, to facilitate risk assessment and decision making.

The approach adopted to meet these objectives is twofold: Preparation of site-specific data sheets for each coastal area identified as particularly vulnerable in terms of exposure to an accidental release of radionuclides (coastal nuclear installations, river mouths, military ports), and development of a computer code to simulate the dispersion of radionuclides in seawater and their transfer to marine organisms.

\section{Materials and methods}

\subsection{Marine data sheets}

For each site identified, a data sheet will be drawn up, listing all information required for preliminary analysis of environmental impact near the release point, as well as planned population protection measures. The purpose of these sheets is to fast provide to experts and decision-makers a first picture of the local issues.

These data sheets must provide all necessary input data, including the identification and characterisation of particularly vulnerable areas as a function of hydrological conditions, and all information required to prepare sampling plans (sampling locations and sample types) for characterization of environmental impact.

These data sheets should therefore include the following:

- Descriptions of dominant sea currents as a function of meteorological or tidal conditions, allowing for rapid identification of vulnerable areas and assessment of corresponding time frames. This information will provide guidance for the implementation of initial population protection actions (prohibition of swimming, fishing or other site-specific activities, suspension of water intake and port operating activities).

- Sampling plans consisting of maps corresponding to different dispersion conditions, including identification of optimal sampling points for contamination assessment purposes.

- Maps showing local site-specific interests, including identification of coastal occupation or activity areas for effective implementation of population protection measures. These maps must also show areas of economic interest (fishing, aquaculture and associated activities, industrial activities requiring water intake, sea therapy) and areas of major ecological interest (protected natural areas, significant ecological sites). These specific data could be provided on a GIS layer to be used to define STERNE model output (see next section).

- List of contact information for local actors in the area considered (port authorities, fishing committees, aquaculture operators, etc.).

\subsection{STERNE simulation tool}

The STERNE simulation tool ("Simulation du Transport et du transfert d'Eléments Radioactifs dans l'environNEment marin", translating as "Simulation of radionuclide transport and transfer in marine environments") is designed to assess the radiological

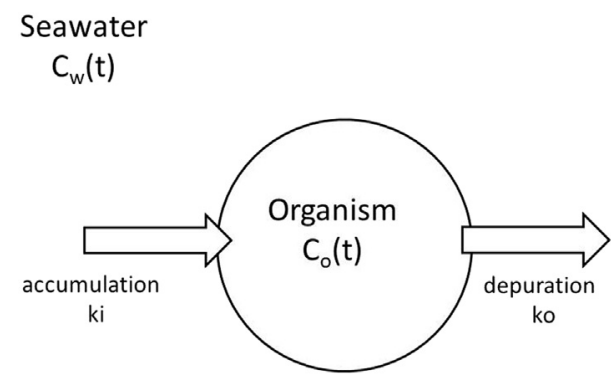

Fig. 3. Biokinetic model of radionuclide transfer from seawater to aquatic organisms. 


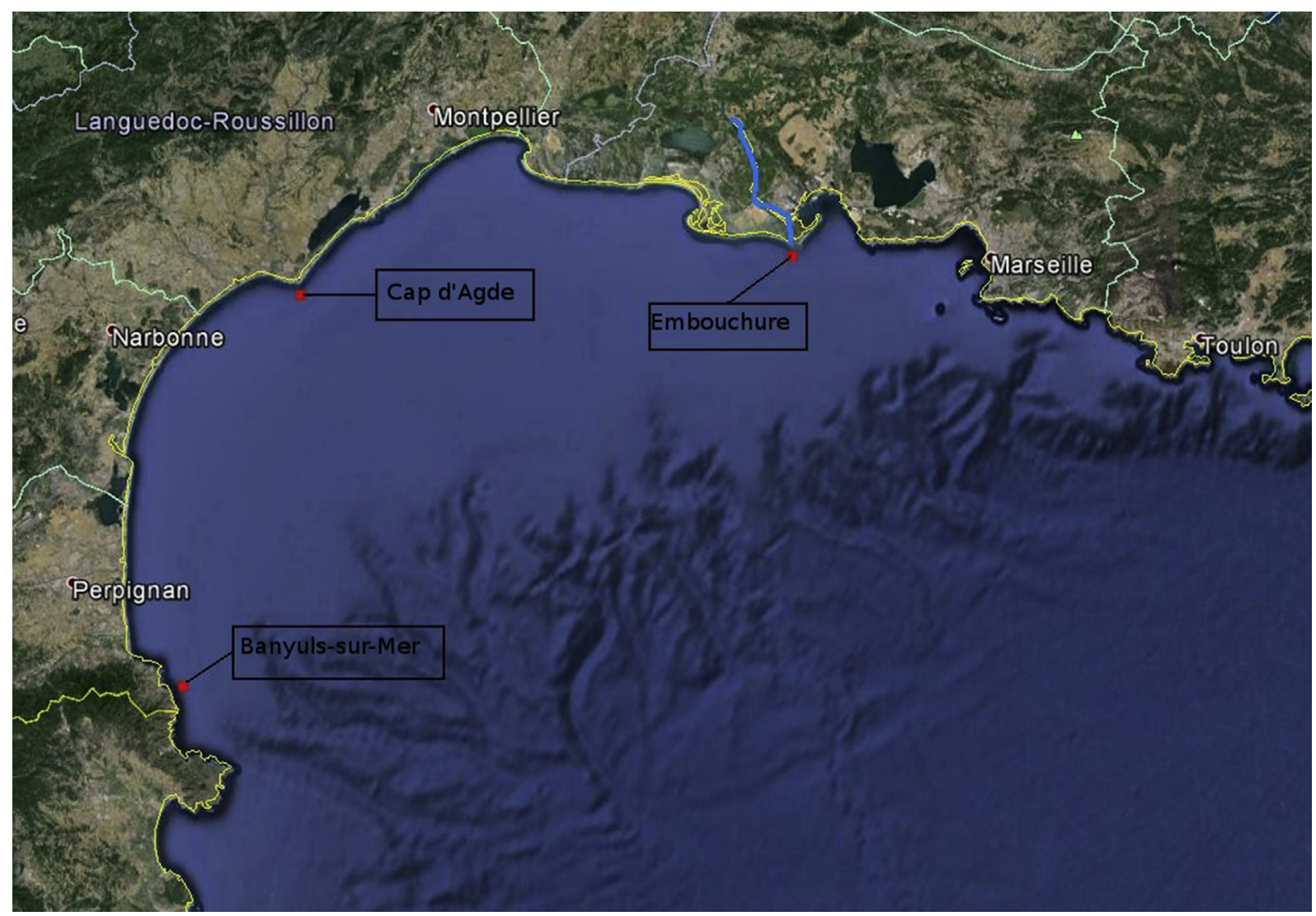

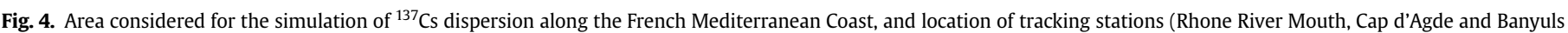
sur Mer).

impact of accidental releases affecting the aquatic environment. Similarly to the atmospheric dispersion simulation tools currently available, this new tool is intended to simulate radionuclide dispersion in seawater and to calculate expected activity concentrations in different biological compartments. The results obtained with STERNE can be used both for predicting the evolution of contamination events and for dose assessment purposes (via postprocessing tools). When cross-referenced with contextual data (also on data sheets previously detailed), these results can be used to define measures prohibiting swimming, fishing or other sitespecific activities, and also to provide guidance for sampling strategies during emergency response and post-accident phases. When used in analysis mode, the STERNE simulation tool can also generate maps of contaminated areas for different site-specific release scenarios (for example, to generate information for marine data sheets).

The implementation principle of the STERNE simulation tool is shown schematically in Fig. 2. The basic principle is the same as for atmospheric dispersion calculations currently performed at IRSN's emergency response centre, with source terms and meteorological data used as input data. For marine dispersion calculations, source terms and hydrodynamic data are fed directly into the simulation tool. For use in emergency situation, the idea is to use hydrodynamic forecasts available for French coastal areas to anticipate consequences for days following the radionuclide input.

\subsubsection{Input data}

The hydrodynamic data serving as the basis for dispersion calculations is supplied as a single NetCDF file including data calculated on a 3D grid. Cumulative water fluxes in $\mathrm{x}, \mathrm{y}$ and $\mathrm{z}$ directions, free surface elevation and diffusion coefficients are available for each mesh and each time step. Cumulative water fluxes are used to calculate the exact quantity of water passing through the grid meshes at each instant, thereby satisfying the continuity equation. Hydrodynamic datasets are generated using the MARS3D model (Model for Applications at Regional Scale; Lazure and Dumas, 2008) developed by IFREMER (French Research Institute for Exploitation of the Sea). The MARS3D model has been previously used and validated by IRSN in various case studies (Bailly du Bois and Dumas, 2005; Duffa et al., 2011; Dufresne et al., 2014). IFREMER generates seven-day hindcasts and forecasts of hydrodynamic conditions in French coastal areas (http://www.previmer.fr), with spatial resolutions of $1.2 \mathrm{~km}$ (Northern Mediterranean Sea, André et al., 2005) and $2.5 \mathrm{~km}$ (Atlantic Coast and English Channel, Lazure et al., 2009). The use of fixed-mesh models with kilometre-scale resolution ensures acceptable calculation times for such large areas. Hydrodynamic models are generated based on hindcasts and forecasts of meteorological and tidal forcing and river flow for major French rivers. Boundary conditions are forced using the Mercator global model (http://www.mercator-ocean.fr/, Ferry et al., 2007).

Source terms are characterised by known quantities of radionuclide releases at known locations (or predefined areas) and instants (or time series). Accidental releases of radionuclides to the marine environment can occur along different pathways and in various modes. Source terms described in data files include release point coordinates, activity input to seawater and their temporal evolution for one or several radionuclides of interest.

Two main types of source terms can be considered:

- Punctual release of a known concentration of one or more radionuclides. Such releases are instantaneous or follow a specific accidental release scenario. STERNE allows users to create 


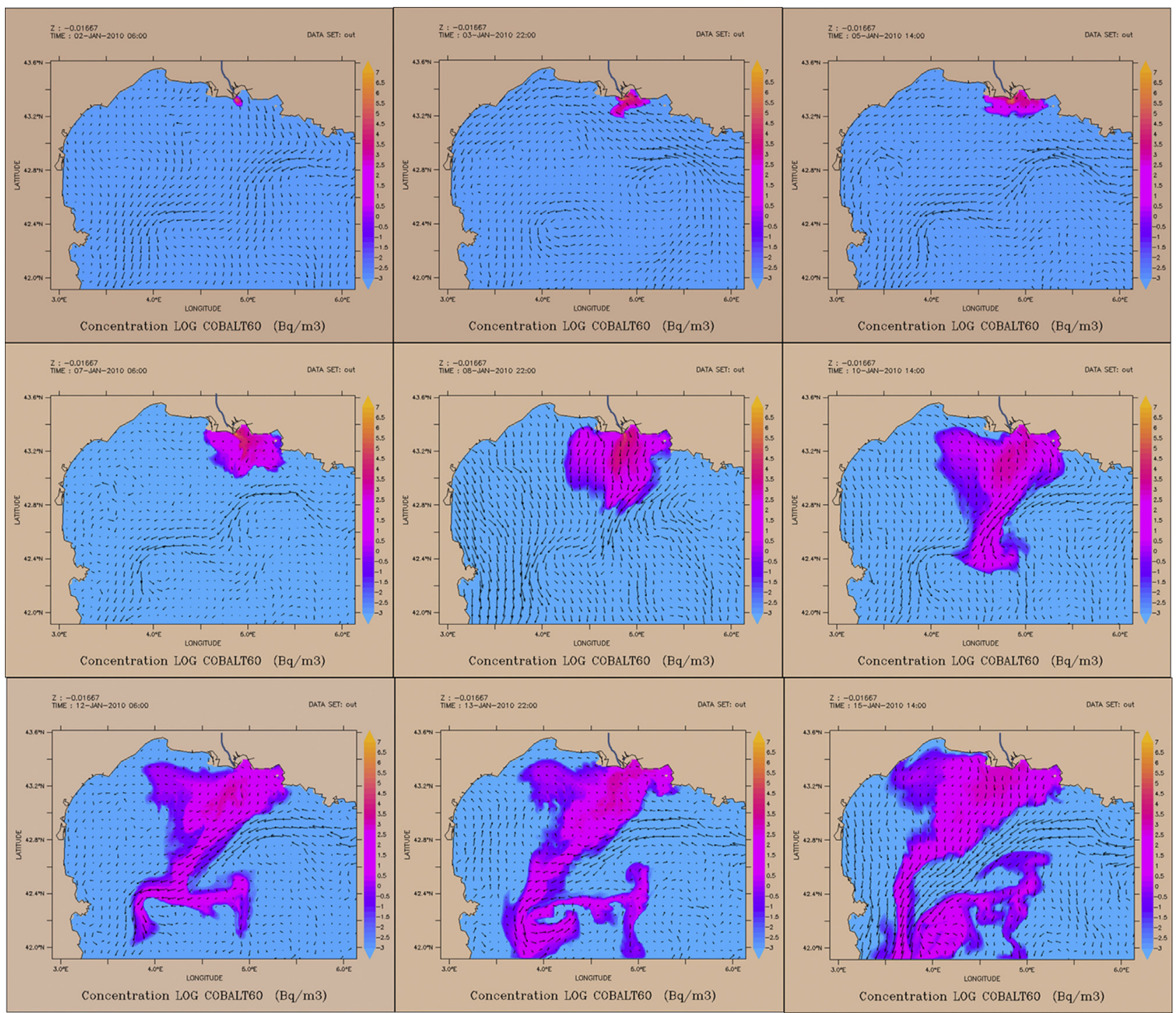

Fig. 5. Example of simulation results for surface dispersion of $10^{14} \mathrm{~Bq}$ of ${ }^{137} \mathrm{Cs}$ discharged from the Rhone River for 7 days (Bq $\mathrm{m}^{-3}$ in surface water, logarithmic scale) starting on 2 January 2010, using realistic hydrodynamic data.

source term description files. The standard example is the Fukushima accident, where a single release point is defined for an accidental release scenario lasting several days and involving several radionuclides (UNSCEAR, 2014).

- Atmospheric radionuclide deposition on sea surface further to accidental release from land-based nuclear installation or nuclear-powered ship. This source term may evolve both spatially and temporally. NetCDF datasets generated by IRSN atmospheric dispersion models can be fed directly into the STERNE simulation tool, which computes interpolated deposition values at hydrodynamic model grid points from atmospheric model data.

\subsubsection{Calculations}

The STERNE simulation tool uses offline calculations of radionuclide dispersion and transfer. A specific FORTRAN95 code has been developed for this purpose.

Eulerian radionuclide dispersion is calculated using a tracer advection-diffusion equation (Equation (1)). $\frac{\partial C}{\partial t}=\operatorname{Div}(\overline{\bar{K}} \vec{\nabla} C)-\vec{\nabla}(\vec{u} C)$

Where: $C$ is the radionuclide concentration

$\overline{\bar{K}}$ is the turbulent diffusion tensor

$\vec{u}$ is the advection current

$t$ is the time elapsed

These calculations take into account the physical decay of each radionuclide considered. Activity concentrations are calculated at each grid point and each time step. Time step values are userdefined based on an acceptable compromise between calculation time and numerical stability. The choice of time step depends on the mesh size and maximum sea current velocity for the area considered. For example, for $1.2 \mathrm{~km}$ resolution (Northern Mediterranean Sea), the time step is set to $50 \mathrm{~s}$.

The STERNE simulation tool uses a radioecological model to calculate activity concentrations in aquatic organisms based on a dynamic transfer approach. Various types of models are available to simulate the transfer of contaminants from seawater to aquatic 

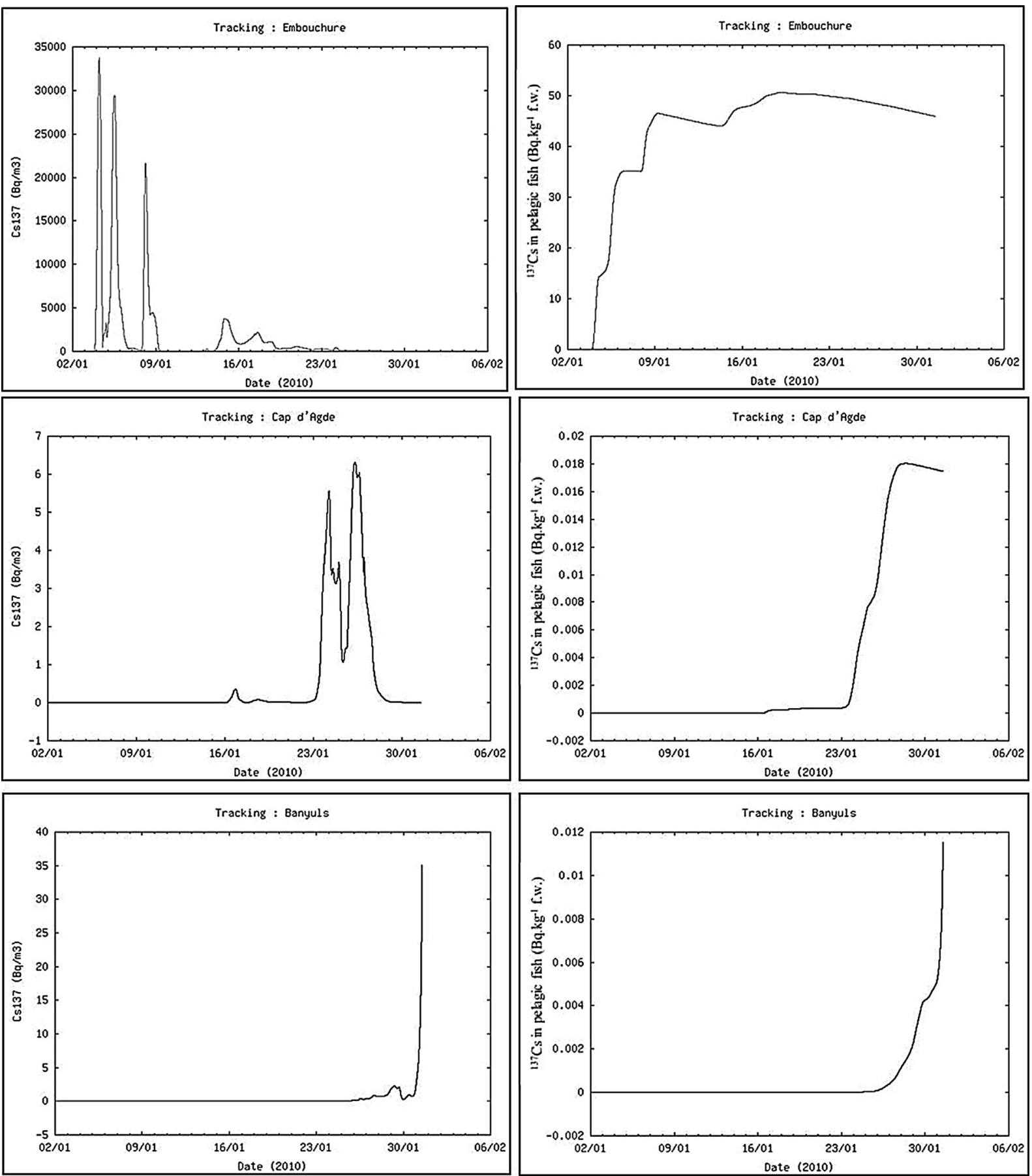

Fig. 6. Concentration time series in seawater $\left(\mathrm{Bq} \mathrm{m}^{-3}\right)$ and pelagic fish $\left(\mathrm{Bq} \mathrm{kg}^{-1} \mathrm{fw}\right)$ at Rhone River Mouth, Cap d'Agde and Banyuls-sur-Mer stations.

organisms. The strategy adopted consists of using a dynamic compartmental model as proposed by Fievet and Plet (2003) and Vives i Batlle et al. (2008). The use of single or multiple compartments to represent an organism allows for a simplified operational model. Actual physiological processes are far more complex (different contamination pathways, e.g. feeding or breathing, different trophic levels, specific physiological parameters such as physical growth or trophic factors). Nevertheless, our approach allows for implementing a relatively simple biokinetic model (Fig. 3) to simulate radionuclide transfers from seawater to the organism of interest based on two types of parameters: concentration factors ( $\mathrm{CF}$, ratio of radionuclide concentration in species considered vs. concentration in seawater) and biological half-lives $\left(\mathrm{T}_{\mathrm{b}}\right)$.

Based on this model, the following equation (Equation (2)) is used to calculate activity concentrations in living organisms for a given concentration in seawater.

$\frac{d C_{o}(t)}{d t}=k_{i} \cdot C_{w}(t)-\left(\lambda_{p}+k_{o}\right) \cdot C_{o}(t)$

where $k_{i}=\left(k_{o}+\lambda_{p}\right) \cdot C F$ 
$C_{o}$ is the activity concentration in the organism $\left(\mathrm{Bq} \mathrm{kg}^{-1}\right.$ fresh weight)

$C_{w}$ is the activity concentration in seawater $\left(\mathrm{Bq}^{-1}\right)$

$k_{i}$ is the uptake or accumulation rate constant $\left(\mathrm{d}^{-1}\right)$

$k_{o}$ is the elimination or depuration rate constant $\left(\mathrm{d}^{-1}\right)$

$\lambda_{p}$ is the physical decay constant $\left(\mathrm{d}^{-1}\right)$

$C F$ is the concentration factor $\left(\mathrm{l} \mathrm{kg}^{-1} \mathrm{f}\right.$.w. $)$

In STERNE code, this equation is computed for a time step i as follows (see Fievet and Plet, 2003 for details):

$C_{o(i)}=a \times C_{o(i-1)}+F C \times(1-a) \times C_{w(i)}$

where $i$ is the time step.

In this equation $a=e^{-T\left(k_{0}+\lambda_{p}\right)}$ where $T=t(i)-t(i-1)$ is the constant time step duration.

In order to refine this one-compartment dynamic model and adapt it to post-accident conditions (for which various studies report multiple depuration rate constants), the STERNE simulation tool allows users to combine two independent compartments as $\mathrm{A} \cdot \mathrm{Co} 1+\mathrm{B} \cdot \mathrm{Co} 2$. A and $\mathrm{B}$ have values between 0 and 1 , and $\mathrm{A}+\mathrm{B}=1$. Each compartment $\mathrm{Co} 1$ and $\mathrm{Co} 2$ has its own transfer parameters (CF and $\mathrm{Tb}$ ).

All required radioecological parameters (concentration factors and single or multi-component biological half-lives) are compiled from literature (IAEA, 2004; Gomez et al., 1991; Vives i Batlle et al., 2007) for main radionuclides and generic marine species (fish, molluscs, crustaceans, algae). Default values can be changed by the user if necessary.

Activity concentrations in organisms are calculated at each 2D calculation grid point and each time step used to calculate seawater activity concentrations. Activity concentrations in bottom fish molluscs, crustaceans and algae are calculated based on bottomwater concentrations. For pelagic fish, two calculations are performed, i.e. based on the mean activity concentration in seawater over the entire water column at the 2D calculation grid point, and based on the maximum activity concentration in the water column at the same grid point.

One limitation of this model is that it does not consider potential contamination pathways associated with bottom sediments, which are still scarcely understood. This can lead to underestimates of activity concentrations in bottom fish exposed to medium or longterm contamination.

\section{Results and discussion}

Calculations performed with the STERNE simulation tool generate values of activity concentrations in seawater at each 3D grid point and at a user-defined time step. Mass concentrations in selected living species (fish, algae, molluscs or crustaceans) are also calculated with the chosen radioecological parameters. These values can be calculated over a spatio-temporal domain smaller than or equal to that of the hydrodynamic input data.

Dispersion and transfer calculations are performed simultaneously on a 3D grid. Results are generated in the form of a global NetCDF file or a set of time-series files for specified tracking points.

As an example, calculations are performed for a theoretical Rhone River accidental ${ }^{137} \mathrm{Cs}$ discharge scenario where a total of $10^{14} \mathrm{~Bq}$ of ${ }^{137} \mathrm{Cs}$ is discharged at a constant rate for 7 days starting on 2 January 2010. Realistic hydrodynamic data provided by the MARS3D model for the North Mediterranean Sea (1.2 km horizontal resolution, 30 vertical layers) is used to calculate radionuclide dispersion over a period of 1 month (from 2 January 2010). The area considered is shown in Fig. 4, and dispersion results are presented on Fig. 5. Three coastal stations are defined as tracking points to export calculated concentration time-series data for seawater and pelagic fish.

Radioecological parameters used to calculate the transfer of ${ }^{137}$ Cs to fish are taken from the literature (IAEA, 2004; Gomez et al., 1991) as follows: $\mathrm{CF}=100$ and $\mathrm{Tb}=58$ days, with one kinetic parameter.

Contaminated freshwater from the Rhone River spreads on the marine surface layer for the first 3 days and then reaches the North Mediterranean Current. Subsequently, contaminated waters shift to the southwest and are transported toward the Spanish coast. Fig. 6 shows the concentration time series in seawater and pelagic fish at the 3 tracking stations. The ${ }^{137} \mathrm{Cs}$ plume reaches the Cap d'Agde station, located $110 \mathrm{~km}$ from the Rhone River discharge point, approximately 22 days after the first discharge to the sea, and it reaches the Banyuls-sur-Mer station, located $165 \mathrm{~km}$ from the Rhone River discharge point, approximately 8 days later. In this dispersion scenario, it is interesting to note the significantly higher seawater activity concentrations at the Banyuls-sur-Mer station, where the main plume of contaminated water is directly advected by the North Mediterranean Current travelling along the continental shelf, as shown by Millot and Taupier-Letage (2005).

Calculated activity concentrations in pelagic fish are shown in Fig. 6, with the concentration time series clearly indicating the persistence of ${ }^{137} \mathrm{Cs}$ in these organisms, due to the 58-day biological half-life used in the transfer model.

The STERNE simulation tool is still in the validation stage and only available for case studies. The accuracy of dispersion simulation results is directly dependent on hydrodynamic forcing and source term realism. It is therefore essential to use forecasts from validated hydrodynamic models, along with the best possible source term characterization. Hydrodynamic conditions simulated by the Mars3D model for French coastal areas well fit with measurements taken over short time intervals (hours, days) but are difficult to verify for longer simulations (weeks, months). Such implementations would require an accurate, validated representation of local hydrodynamics, such as for example that produced for the Toulon area (Duffa et al., 2011; Dufresne et al., 2014).

The modelling approach chosen to simulate transfers to marine biota still needs to be validated. Additional kinetic parameters for the simulation of transfers between seawater and marine organisms also need to be more documented.

At this stage, considering the intended use as an emergency response tool, only dissolved-phase dispersion modelling is applied. In order to take into account the fraction of radionuclides attached to suspended sediment particles, it would be necessary to include a sediment transport module to be run with the hydrodynamic model. The integration of such a module is relatively complex and computation-time consuming and, most importantly, would require adjustment to in situ measurements of various sediment-specific parameters. Sediment transport modelling could be subsequently implemented for more in-depth calculations during post-emergency phases. It is therefore not included in the initial development.

\section{Conclusion}

IRSN developed two complementary tools for use in the event of a radiological marine accident at French coastal areas. Site-specific marine data sheets will allow for initial assessment of potential consequences and will help experts define sampling and monitoring strategies. The implementation of STERNE model within global IRSN crisis centre decision support system will offer experts a set of tools covering all environmental compartments and usable in real time emergency situations. 


\section{Acknowledgements}

The authors would like to thank the IFREMER modelling team for its support and use of the Caparmor computational server.

\section{References}

André, G., Garreau, P., Garnier, V., Fraunié, P., 2005. Modelling variability of the sea surface circulation in the North-Western Mediterranean Sea and in the Gulf of Lions. Ocean. Dyn. 55, 294-308.

Bailly du Bois, P., Dumas, F., 2005. Fast hydrodynamic model for of medium- and long-term dispersion in seawater in the English Channel and southern North Sea, qualitative and quantitative validation by radionuclide tracers. Ocean. Model. 9 (2), 169-210.

Duffa, C., Dufois, F., Coudray, S., 2011. An operational model to simulate postaccidental radionuclide transfers in Toulon marine area : preliminary development. Ocean. Dyn. http://dx.doi.org/10.1007/s10236-011-0429-0.

Dufresne, C., Duffa, C., Rey, V., 2014. 3D circulation in the Bay of Toulon and water exchanges at the Little Bay fairway. Ocean. Dyn. 64 (2), 209-224.

Ferry, N., Rémy, E., Brasseur, P., Maes, C., 2007. The Mercator global ocean operational analysis system: assessment and validation of an 11-year reanalysis. J. Mar. Syst. 65 (1-4), 540-560.

Fievet, B. Plet, D. 2003. Estimating biological half-live of radionuclides in marine compartments from environmental time-series measurements. J. Environ. Radioact. 65, 91-107.

Gomez, L.S., Marietta, M.G., Jackson, D.W., 1991. Compilation of Selected Marine Radioecological Data for the Formerly Utilized Sites Remedial Action Program: Summaries of Available Radioecological Concentration Factors and Biological Half-lives. SANDIA Report, SAND89-1585.

IAEA, 2004. Technical Report Series No. 422. Sediment distribution coefficients and concentration factors for biota in the marine environment.

Korsakissok, I., Mathieu, A., Didier, D., 2013. Atmospheric dispersion and ground deposition induced by the Fukushima Nuclear power plant accident: a localscale simulation and sensitivity study. Atmos. Environ. 70, 267-279.
Lazure, P., Dumas, F., 2008. An external-internal mode coupling for a 3D hydrodynamical model for applications at regional scale (MARS). Adv. Water Resour. 31 (2), 233-250.

Lazure, P., Garnier, V., Dumas, F., Herry, C., Chifflet, M., 2009. Development of a hydrodynamic model of the Bay of Biscay. Validation of hydrology. Cont. Shelf Res. 29 (8), 985-999.

Mathieu, A., Korsakissok, I., Quélo, D., Groëll, J., Tombette, M., Didier, D., Quentric, E. Saunier, O., Benoît, J.-P., Isnard, O., 2011. Atmospheric dispersion and deposition of radionuclides from the Fukushima Daiichi Nuclear Power Plant accident Elements 8 (3). http://dx.doi.org/10.2113/gselements.8.3.195, 1811-5209/12/ 0008-0195\$2.50.

Millot, C., Taupier-Letage, I., 2005. In: Saliot, Alain (Ed.), Circulation in the Mediterranean Sea. The Handbook of Environmental Chemistry, vol. 5 Part K Springer Verlag, Berlin Heidelberg, pp. 29-66.

Okuda, K., Ohashi, M., 2012. On the studies of recovery and reconstruction of fisheries hit by the Great East Japan earthquake. Procedia Technol. 5, 208-214.

Povinec, P., Hirose, K., Aoyama, M., 2013. Fukushima Accident: Radioactivity Impact on the Environment. Elsevier, ISBN 978-0-12-408132-1.

Saunier, O., Mathieu, A., Didier, D., Tombette, M., Quélo, D., Winiarek, V., Bocquet, M., 2013. An inverse modeling method to assess the source term of the Fukushima Nuclear Power Plant accident using gamma dose rate observations. Atmos. Chem. Phys. 13, 11403-11421. http://dx.doi.org/10.5194/acp-13-114032013.

Science-Council-of-Japan, 2014. A review of the model comparison of transportation and deposition of radioactive materials released to the environment as a result of the Tokyo Electric Power Company's Fukushima Daiichi Nuclear Power Plant accident. Science Council of Japan. In: Sectional Committee on Nuclear Accident Committee on Comprehensive Synthetic Engineering. S.C.o.J, $111 \mathrm{p}$.

UNSCEAR, 2014. Sources, Effects and Risks of Ionizing Radiation - UNSCEAR 2013 Report to the General Assembly with Scientific Annexes, vol. 1. United Nation.

Vives i Batlle, J., Wilson, R.C., McDonald, P., 2007. Allometric methodology for the calculation of biokinetic parameters for marine biota. Sci. Total Environ. 388 256-269.

Vives i Batlle, J., Wilson, R.C., Watts, S.J., Jones, S.R., McDonald, P., Vives-Lynch, S., 2008. Dynamic model for the assessment of radiological exposure to marine biota. J. Environ. Radioact. 99, 1711-1730. 